\title{
Spor Takımı Evangelizmi (eFANgelizm) Ölçeğinin Türkçeye Uyarlanması: Güvenirlik ve Geçerlilik Çalışması
}

\author{
Zeki YÜKSEKBİLGİLI*
}

\begin{abstract}
$\ddot{O Z Z}$
Taraftarı olan spor organizasyonlarının ana amaçları kendilerine bağlı spor tüketicileri oluşturmaktır. Bu bağlamda, spor yönetimi alanında birçok akademik araştırma spor takımı bağlllığı konusuna odaklanmiştır. Bu çalı̧̧mada amaç, Dwyer, Greenhalgh ve LeCrom tarafindan 2015 yılında İngilizce olarak geliştirilen Spor Takımı Evangelizmi (Fangelizm) Ölçeğinin (STEÖ) Türkçeye uyarlanmasıdır. Orijinal ölçek 14 soru ve 4 faktöre sahiptir. Çallşma sonucunda 550 kişiden elde edilen veriler üzerinden STEÖ'nin Türkçe formunun güvenilirlik değeri ,936 ve geçerlilik değeri 0,845 olarak belirlenmiştir. Elde edilen Türkçe formda 2 soru silinmiştir. Spor Takımı Evangelizmi (eFANgelizm) Ölçeğinin Türkçe formu, spor takımı evangelizmini ölçmede geçerli ve güvenilir bir araçtır.
\end{abstract}

Anahtar Kelimeler: Spor Takımı Evangelizmi Ölçeği, Efangelizm, Geçerlilik, Güvenilirlik JEL Sinıflandırması: M31, M21, D19

\section{Adaptation of Sport eFANgelism Scale to Turkish: Validity and Reliability Study}

\section{ABSTRACT}

Developing loyal sport consumers is a fundamental goal of spectator sport organizations. As a result, a great deal of sport management academic research has focused on the concept of sport team loyalty. In this study, it was aimed to adopt the Sport eFANgelism Scale developed in English in 2015 by Dwyer, Greenhalgh and LeCrom to Turkish. The original scale has 14 questions and four factors. The Cronbach alpha coefficient of the whole scale was found as ,936 and reliability coefficient estimated from the data of 550 individuals was found as 0,845. In the Turkish version of Sport eFANgelism Scale, two questions were deleted. The Turkish form of the Sport eFANgelism Scale is a valid and reliable instrument in the assessment of sport efangeism.

Key Words: Sport Efangelism Scale, Fangelism, Validity, Reliability

JEL Classification: M31, M21, D19

\section{GİRIŞ}

21. yüzyıl, futbolun insanlık tarihindeki yolculuğunda, popülaritesinin en üst seviyeye ulaştığı dönemdir. Spor araştırmalarında, revizyonist yaklaşımlardan milliyetçiliğe, boş zamanlar sosyolojisinden eğlence kültürüne, sosyal dayanışmadan şiddete, ideolojik etkilerden ekonomiye değin birçok alan ve kavramla iç içe olan futbol, modernliği ikon kabul eden günümüz insanının paradoksunu anlamada ve değerlendirmede de önemli bir göstergedir. Futbol, sosyolojik anlamıyla takım kimliği perspektifinde, taraftar ve profesyonel oyuncu

* Yrd.Doç.Dr. Nişantaşı Üniversitesi, İktisadi İdari ve Sosyal Bilimler Fakültesi, yuksekbilgili@gmail.com 
için ortak kodların paylaşımıdır (Eker Öğüt, 2010: 180). 21. yüzyılda gerçekleşen bireyselleşme sonucunda, insan yabancılaşma ve yalnızlaşma duygusuna karşı koymaya çalışmaktadır. Bunun için de aitlik duygusuyla, kendini güvende ve mutlu hissedebileceği bir cemaat, bir grup, bir kulüp, bir dernek gibi herhangi bir sosyal grubun üyesi olmak istemektedir.

Özellikle son dönemde, spor takımı taraftarlı̆̆ı, başlı başına bir endüstri haline gelmiştir. Hatta futbol, ilaç endüstrisini bile geride bırakabilecek bir büyüklüğe ulaşmıştır. İşte bu noktada spor kulüplerinin ve bu kulüplerin taraftarına yönelik spor ürünleri üreten işletmelerin, taraftarların davranışlarını anlayabilmeleri ve pazarlama stratejilerini bu doğrultuda belirlemeleri önem arz etmektedir.

$\mathrm{Bu}$ çalışmada amaç, Dwyer, Greenhalgh ve LeCrom (2015) tarafından İngilizce olarak geliştirilen Spor Takımı Evangelizmi (Fangelizm) Ölçeğinin (STEÖ) Türkçeye uyarlanmasıdır. Dwyer, Greenhalgh ve LeCrom (2015) ölçeği geliştirirken, "evangelizm" sözcügünün içerisine "fanatik" kelimesinin kısaltması olan "fan" sözcüğünü yerleştirerek "eFANgelizm" kelimesini ortaya atmışlardır.

STEÖ, bireysel olarak bir spor takımı taraftarının spor takımı markasına yönelik evangelist tutumunu ölçmektedir.

\section{TEMEL KAVRAMLAR}

\section{A. Marka Evangelizmi}

Marka evangelisti, aktif olarak başkalarının satın alma davranışını pozitif yönde etkilemek için bir markanın tanıtımını yapan ve markayla ilgili iyi haberlerin yayılmasına katkı sağlayan ve bu katkıyı herhangi bir beklenti içerisine girmeden gerçekleştiren tüketiciler olarak ele alınmaktadır (Matzler vd., 2007). İşletme ile müşteri arasında oluşturulan bu duygusal deneyimin içselleştirilmesi tüketicilerin kimlik, topluluk ve aidiyet duygularına hitap edecek şekilde benlik imajına dönüştürülebilir. $\mathrm{Bu}$ şekilde bir tanımlama, markanın gelecekteki sadakatinin korunmasını sağlayabilecektir (Hanlon, 2006). Roberts (2004), evangelistler arasındaki bağlılığın markaya duyulan sevgi ya da tutkuyu da geçerek "aklın ötesinde bir sadakat" boyutunu da aştığını belirtmektedir.

\section{B. Fanatizm}

Futbol, modern dünyada, yüksek teknolojik donanımlı stadyumları, yaşamın her alanını kuşatabilen reklamları, özel TV kanalları, uzmanları, medya araçları, kupa, tişört, forma gibi maddî kültür ürünlerinin ranta dönüştügü butik mağazaları, yüksek transfer ücretleri, futbolcuları, teknik direktörleri, çalışanları ve taraftarları ile hayal gücünü zorlayan dev bir endüstri alanıdır. Futbol endüstrisinin en önemli destekleyici faktörü ise, fanatik taraftardır. Fanatiklik, gönüllü katılım içinde gerçekleştirilen bir kent ritüelidir. Grup üyeliğinin verdiği mutluluğu yaşama ve aitlik duygusu, sosyal bir varlık olan insanın sosyalizasyon zincirini oluştururken yararlandığı kültürel değerlerden biridir (Eker Öğüt, 2010: 173).

Taraftar, popüler futbol kültürünün, toplumun mikro ekonomik bir temsilini ve yeniden kuruluşunu ifade eden bir cemaat türü olarak tanımlanır (Meriç, 1994: 30). Taraftar belirli bir takıma/takımlara karşı bağlılık duygusu 
taşıyan, kulübün hizmetlerini belirli bir ücret ödeyerek satın alan bireylere atfedilen bir ifade olarak karşımıza çıkmaktadır (Aycan, Polat ve Uçan, 2009: 170). Taraftarlar spor kulüplerinin hedef kitlesi olarak pazarlama çabalarının yoğunlaştırılmasını gerektiren spor tüketicisi grubudur (Orçun ve Demirtaş, 2015: 116).

\section{Spor Takımı Evangelizmi (eFANgelizm) Öıçeği}

Dwyer, Greenhalgh ve LeCrom tarafindan 2015 yllinda İngilizce olarak geliştirilen Spor Takımı Evangelizmi (Fangelizm) Ölçeği (STEÖ) 14 sorudan oluşmaktadır. Soruların yanıtlanması için 5'Li likert ölçeği kullanılmıştır. 4 faktörlü yapıya sahip olan ölçekte 1, 2, 3, 4 numaralı sorular 'avukat' (A) faktörünü, 5, 6, 7, 8 numaralı sorular 'reklam' (A) faktörünü, 9, 10,11 numaralı sorular 'kışkırtma' (K) faktörünü ve 12, 13, 14 numaralı sorular 'özümsemek' (O) faktörünü ölçmektedir.

'Avukat faktörü', taraftarın kendi takımını diğer takımlarına göre üstün görmesi (yabancılara dahi) bu konuda avukatlık yapmasını ifade etmektedir. 'Reklam faktörü', takıma bağlılığın araçlarda, işte, çevrimiçi ve diğerlerine hediyelerde yer almasını ifade etmektedir. 'Kışkırtma faktörü' ise, başka bir takımın taraftarı olan aile üyelerinin / arkadaşların kışşkırtıcı hareketlere maruz bırakılmasını ifade etmektedir. Son olarak, 'özümseme faktörü' taraftarların kendi aralarında oyun günlerinde gerçekleştirdiği özümsemeyi ifade etmektedir.

Orijinal ölçekte bulunan sorular ve ölçtükleri faktörler Tablo 1'de listelenmiştir.

Tablo 1: Orijinal Ölçekte Bulunan Sorular ve Ölçtükleri Faktörler

\begin{tabular}{|l|l|}
\hline Faktör & \multicolumn{1}{|c|}{ Sorular } \\
\hline Avukat (A) & $\begin{array}{l}\text { A1. Çevremdekiler, tuttuğum takımın diğerlerine göre üstün olduğu } \\
\text { konusunda ikna etmeye çalışırım. }\end{array}$ \\
\cline { 2 - 3 } & A2. Tuttuğum takımdan "biz" şeklinde bahsederim. \\
\cline { 2 - 3 } & A3. Çevremdekiler tuttuğum takımın iyi oyuncularından bahsederim. \\
\cline { 2 - 3 } & $\begin{array}{l}\text { A4. Tuttuğum takım ile ilgili tanımadı̆̆ım kişilerin konuşmalarına dâhil } \\
\text { olurum. }\end{array}$ \\
\hline Reklam (R) & R1. Aracımda tuttuğum takımı belirten ürünler bulunur. \\
\cline { 2 - 3 } & R2. Ofisimde tuttuğum takımı belirten ürünler bulunur. \\
\cline { 2 - 3 } & $\begin{array}{l}\text { R3. Doğum günlerinde, özel günlerde tuttuğum takıma ait ürünleri hediye } \\
\text { olarak veririm. }\end{array}$ \\
\cline { 2 - 3 } & R4. İnternet profillerimde tuttuğum takımı belirtirim. \\
\hline K1şkırtma (K) & $\begin{array}{l}\text { K1. Tuttuğum takımı tutmayan arkadaşlar ve aile üyeleri ile onların tuttuğu } \\
\text { takım kaybettiğinde iletişim kurarım. }\end{array}$ \\
\cline { 2 - 3 } & $\begin{array}{l}\text { K2. Tuttuğum takımı tutmayan arkadaşlar ve aile üyeleri ile onların tuttuğu } \\
\text { takım kazandığında iletişim kurarım. }\end{array}$ \\
\cline { 2 - 3 } & $\begin{array}{l}\text { K3. Tuttuğum takımı tutmayan arkadaşlar ve aile üyeleri ile onların tuttuğu } \\
\text { takım oynarken iletişim kurarım. }\end{array}$ \\
\hline \multirow{5}{*}{$\begin{array}{l}\text { Özümsemek } \\
\text { (O) }\end{array}$} & $\begin{array}{l}\text { O1. Tuttuğum takımın maçını arkadaşlar, aile üyeleri ile bir araya gelerek } \\
\text { seyrederim. }\end{array}$ \\
\cline { 2 - 3 } & O2. Tuttuğum takımın maçının olduğu günlerde takım üniformas1 giyerim. \\
\cline { 2 - 3 } & $\begin{array}{l}\text { O3. Aynı takımı tutan arkadaşlar ve aile üyeleri ile tuttuğumuz takım } \\
\text { oynarken iletişim kurarım. }\end{array}$ \\
\hline
\end{tabular}


Orijinal ölçeğin güvenilirlik sonuçları; 'avukat' (A) faktörü için ,539, 'reklam' (A) faktörü için ,471, 'kışkırtma' (K) faktörü için ,608 ve 'özümsemek' (O) faktörü için ,601 olarak belirlenmiştir.

\section{ARAŞTIRMA}

\section{A. Araştırmanın Amacı}

$\mathrm{Bu}$ araştırmanın amacı, Dwyer, Greenhalgh ve LeCrom (2015) tarafindan geliştirilen Spor Takımı Evangelizmi (Fangelizm) Ölçeğinin (STEÖ) Türkçeye uyarlanması, uyarlanan ölçeğin güvenirlik ve geçerlilik çalışmasını tamamlamaktır.

\section{B. Araştırmanın Örneklemi}

$\mathrm{Bu}$ araştırmada anket araştırma tekniğinden yararlanılmıştır. Araştırmanın evreni Türkiye'de yaşayan tüm kişilerdir. Araştırmanın örneklemini Türkiye'de bulunan ve bilgisayar kullanan tüm kullanıcılar oluşturmaktadır. Anket uygulamasının devam ettiği tarihler arasında (05 Şubat 2016 - 30.03.2016) toplam 550 anket doldurulmuştur.

Araştırma kapsamında 550 farklı kullanıcıdan tarafından cevaplanan anketler kullanılmıştır. Çalışmada kullanılan anket, çevrimiçi (online) olarak yayınlanmış ve çalışma sonucunda toplam 550 adet anket yanıtlandığında, anket kullanıma kapatılmıştır. Aynı kullanıcının birden fazla anket doldurması engellemek amaciyla IP kontrolü yapılmış ve aynı IP'ye sahip kullanıcıların birden fazla anket doldurulması engellenmiştir.

\section{Verilerin Toplanması ve Değerlendirilmesi}

Örneklem grubundan elde edilen verilerin analizi; SPSS 22 Paket Programı (Statistical Programme for Social Sciences / Sosyal Bilimler için İstatistik Paket Programı) vasıtasıyla yapılmıştır. Ölçeğin faktör yapısı açımlayıcı faktör analizi ve varimaks rotasyonu ile incelenmiştir. Güvenilirlik analizinde Cronbach alfa katsayıları kullanılmıştır.

Elde edilen veriler bilgisayarda SPSS 22 programında çözümlenmiş, manidarlıklar .05 düzeyinde sınanmış, diğer manidarlık düzeyleri ayrıca belirtilmiş ve bulgular araştırmanın amaçlarına uygun olarak tablolar halinde sunulmuştur.

\section{BULGULAR}

\section{A. Araştırmanın Betimsel İstatistikleri}

Araştırma kapsamında 550 kişi ile anket yapılmıştır. Katılımcıların 250 tanesi kadın ve 290 tanesi erkektir (Tablo 1). Katılımcıların 180 tanesi 1980'den önce doğumlulardan, 370 tanesi 1980-1999 arası doğumlulardan (Tablo 2) oluşmaktadır. Çalışmada kuşaklara göre farkların araştırılabilmesi için bu yaş aralığ 1 baz alınmıştır. Katılımcılardan 230 tanesi bekar ve 320 tanesi evlidir (Tablo 3). Katılımcılardan 350 tanesinin çocuğu yokken, bir çocuğa sahip olanların sayısı 150, iki çocuğa sahip olanların sayısı 30 , üç ve daha fazla çocuğu olanların sayısı ise 20'dir (Tablo 4). 20 katılımcı ilkokul, 90 katılımc lise, 80 katılımcı önlisans, 150 katılımcı lisans ve 210 katılımcı yükseklisans mezunudur (Tablo 5). 
Tablo 2. Katılımcıların Cinsiyetlerine Göre Dağglımı

\begin{tabular}{|c|c|c|c|}
\hline \multicolumn{2}{|c|}{ Kadın } & \multicolumn{2}{|c|}{ Erkek } \\
\hline $\mathrm{N}$ & $\mathrm{N} \%$ & $\mathrm{~N}$ & $\mathrm{~N} \%$ \\
\hline 260 & $47,3 \%$ & 290 & $52,7 \%$ \\
\hline
\end{tabular}

Tablo 3. Katılımcıların Yaşlarına Göre Dağılımı

\begin{tabular}{|c|c|c|c|c|c|}
\hline \multicolumn{2}{|c|}{1980 'den önce } & \multicolumn{2}{c|}{$1980-1999$ arası } & \multicolumn{2}{c|}{ 1999'dan sonra } \\
\hline $\mathrm{N}$ & $\mathrm{N} \%$ & $\mathrm{~N}$ & $\mathrm{~N} \%$ & $\mathrm{~N}$ & $\mathrm{~N} \%$ \\
\hline 180 & $32,7 \%$ & 370 & $67,3 \%$ & 0 & $0,0 \%$ \\
\hline
\end{tabular}

Tablo 4. Katılımcıların Medeni Durumlarına Göre Dağılımı

\begin{tabular}{|c|c|c|c|}
\hline \multicolumn{2}{|c|}{ Bekâr } & \multicolumn{2}{c|}{ Evli } \\
\hline $\mathrm{N}$ & $\mathrm{N} \%$ & $\mathrm{~N}$ & $\mathrm{~N} \%$ \\
\hline 230 & $41,8 \%$ & 320 & $58,2 \%$ \\
\hline
\end{tabular}

Tablo 5. Katılımcıların Çocuk Sahipliklerine Göre Dağılımı

\begin{tabular}{|c|c|c|c|c|c|c|c|}
\hline \multirow{2}{*}{ Bir çocuk } & \multicolumn{2}{c|}{ İki Çocuk } & \multicolumn{2}{c|}{$\begin{array}{c}\text { 3 ve Daha Fazla } \\
\text { Çocuk }\end{array}$} & \multicolumn{2}{c|}{ Çocuğum Yok } \\
\hline $\mathrm{N}$ & $\mathrm{N} \%$ & $\mathrm{~N}$ & $\mathrm{~N} \%$ & $\mathrm{~N}$ & $\mathrm{~N} \%$ & $\mathrm{~N}$ & $\mathrm{~N} \%$ \\
\hline 150 & $27,3 \%$ & 30 & $5,5 \%$ & 20 & $3,6 \%$ & 350 & $63,6 \%$ \\
\hline
\end{tabular}

Tablo 6. Katılımcıların Eğitim Durumlarına Göre Dağılımı

\begin{tabular}{|c|c|c|c|c|c|c|c|c|c|}
\hline \multicolumn{2}{|c|}{ İlköğretim } & \multicolumn{2}{c|}{ Lise } & \multicolumn{2}{c|}{ Önlisans } & \multicolumn{2}{c|}{ Lisans } & \multicolumn{2}{c|}{ Yükseklisans } \\
\hline $\mathrm{N}$ & $\mathrm{N} \%$ & $\mathrm{~N}$ & $\mathrm{~N} \%$ & $\mathrm{~N}$ & $\mathrm{~N} \%$ & $\mathrm{~N}$ & $\mathrm{~N} \%$ & $\mathrm{~N}$ & $\mathrm{~N} \%$ \\
\hline 20 & $3,6 \%$ & 90 & $16,4 \%$ & 80 & $14,5 \%$ & 150 & $27,3 \%$ & 210 & $38,2 \%$ \\
\hline
\end{tabular}

\section{B. Araştırmanın Bulguları}

Ölçeğin Türkçeye uyarlanması için ölçeği geliştirmiş olan yazarlar ile bağlantı kurularak izin alınmıştır. 15 Şubat 2016 tarihinde tüm yazarlar adına Brendan Dwyer ölçeğin Türkçeye uyarlanması için izin verdiğini yazılı olarak beyan etmiştir. Ölçek önce sosyal bilimler alanında akademisyen olarak çalışan beş kişi tarafından Türkçeye çevrilmiştir. Geri çeviri yine akademisyen olan beş kişiden oluşan farklı bir grup tarafından yapılmıştır.

İstatistiğe yönelik öz-yeterlik ölçeğinin Türkçe versiyonunun yapısını incelemek amacıyla SPSS 22 paket programı kullanılarak faktör analizi yapılmıştır. Faktör analizinden önce Cronbach alfa katsayısı hesaplanmış ve 0,936 bulunmuştur.

Ayrıca maddelerin hiç birinin güvenirliği düşürmediği saptanmıştır. Soru silindiğinde Cronbach Alfa değerinin ne olacağı sorgulanmış ve Tablo 7'de bulunan veriler elde edilmiştir. 
Tablo 7. Soru Silindiğinde Elde Edilecek Ölçek Değerleri

\begin{tabular}{|l|r|r|r|}
\hline Soru & $\begin{array}{c}\text { Soru silindiğinde elde } \\
\text { edilecek ölçek ortalaması }\end{array}$ & $\begin{array}{c}\text { Soru silindiğinde elde } \\
\text { edilecek ölçek varyans } \\
\text { değeri }\end{array}$ & $\begin{array}{c}\text { Soru Silindiğinde Elde } \\
\text { Edilecek Ölçek } \\
\text { Güvenilirlik Değeri (a) }\end{array}$ \\
\hline A1 & 29,9091 & 203,143 &, 935 \\
\hline A2 & 29,2727 & 198,122 &, 933 \\
\hline A3 & 29,6545 & 198,951 &, 931 \\
\hline A4 & 30,2909 & 199,150 &, 930 \\
\hline R1 & 30,0909 & 191,777 &, 928 \\
\hline R2 & 30,0545 & 191,017 &, 928 \\
\hline R3 & 30,4182 & 197,839 &, 930 \\
\hline R4 & 29,4909 & 190,560 &, 929 \\
\hline K1 & 30,1636 & 196,676 &, 929 \\
\hline K2 & 30,4727 & 208,155 &, 934 \\
\hline K3 & 30,0182 & 197,869 &, 931 \\
\hline O1 & 29,4364 & 203,962 &, 935 \\
\hline O2 & 30,1636 & 200,866 &, 932 \\
\hline O3 & 29,8727 & 196,031 &, 929 \\
\hline
\end{tabular}

Faktör analizinin bir varsayımı verinin dağılımının faktör analizi yapmaya uygun olup olmadığını belirten Kaiser-Meyer-Olkin (KMO) katsayısıdır. SPSS tarafindan rapor edilen KMO katsayısı 0,845 bulunmuştur. Bu değer faktör analizi yapmak için oldukça iyi bir değerdir (Pett, Lackey ve Sullivan, 2003: 78; Büyüköztürk, 2004).

Araştırma sonucunda elde edilen güvenilirlik değerleri Tablo 8'de özetlenmiştir.

Tablo 8. Ölçeğe Ait Güvenilirlik Değerleri

\begin{tabular}{|c|c|}
\hline Güvenilirlik Değeri (Cronbach's Alfa) & $\boldsymbol{\alpha}$ \\
\hline Faktör 1: Avukat (A) &, 830 \\
\hline Faktör 2: Reklam (R) &, 882 \\
\hline Faktör 3: K1şkırtma (K) &, 826 \\
\hline Faktör 4: Özümsemek (O) &, 823 \\
\hline Tüm Ölçek &, 936 \\
\hline
\end{tabular}

Faktör analizi sonucunda ortak varyans değerleri hesaplanmış (Tablo 9) ve sorunlu bir soru olmadığı gözlemlenmiştir. 
Tablo 9. Ortak Varyans Değerleri

\begin{tabular}{|c|c|}
\hline Soru & Ortak varyans değeri \\
\hline A1 &, 748 \\
\hline A2 &, 822 \\
\hline A3 &, 646 \\
\hline A4 &, 666 \\
\hline R1 &, 674 \\
\hline R2 &, 720 \\
\hline R3 &, 661 \\
\hline R4 &, 702 \\
\hline K1 &, 745 \\
\hline K2 &, 669 \\
\hline K3 1 &, 822 \\
\hline O2 &, 711 \\
\hline O3 &, 710 \\
\hline
\end{tabular}

Ölçeğin kaç boyutlu olması gerektiğine karar verilebilmesi için öncelikle scree plot grafiği (Şekil 1) incelenmiştir. Bunun sonucunda scree plot grafiğinde; birinci noktadan ikinci noktaya keskin bir düşüş olduğu ve ikinci noktadan sonra çizginin eğimi yatay bir seyre geçtiği gözlemlenmiştir. Dolayısıyla, ikinci noktanın üzerinde kalan nokta sayısı (ya da ikinci noktaya kadar olan aralık sayıs1) faktör sayısı hakkında bilgi vermektedir. Bu grafik incelendiğinde ölçeğin tek boyutlu olarak kabul edilebileceği görülmektedir.

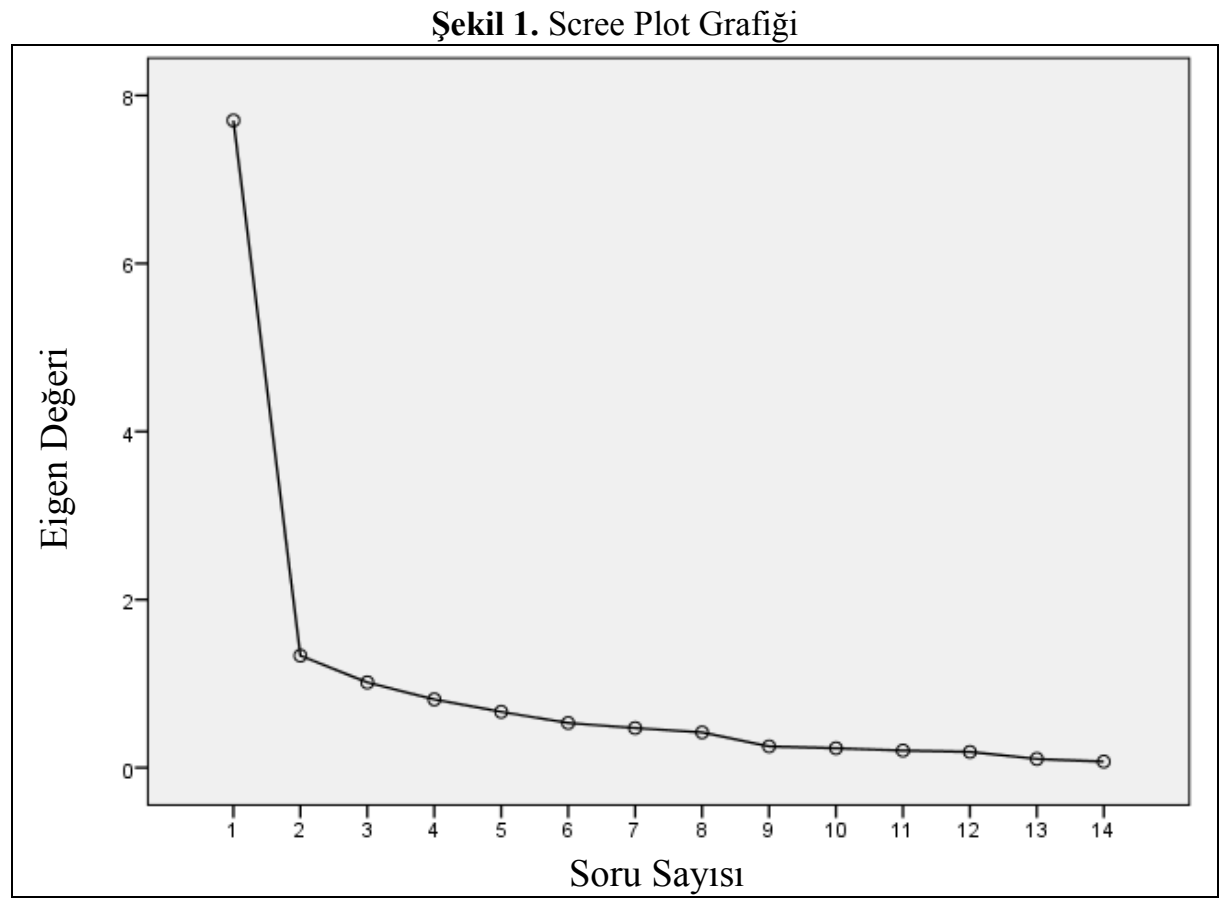


Tek faktörlü yapıya göre faktör analizi tekrar yapıldığında ortak varyans değerleri Tablo 10'da gösterildiği şekilde elde edilmiştir.

Tablo 10. Tek Faktörlü Yapıya Göre Ortak Varyans Değerleri

\begin{tabular}{|c|c|}
\hline Soru & Ortak varyans değeri \\
\hline A1 &, 371 \\
\hline A2 &, 438 \\
\hline A3 &, 530 \\
\hline A4 &, 604 \\
\hline R1 &, 671 \\
\hline R2 &, 686 \\
\hline R3 &, 601 \\
\hline K1 &, 636 \\
\hline K2 &, 654 \\
\hline K3 &, 420 \\
\hline O1 &, 565 \\
\hline O2 &, 379 \\
\hline O3 &, 505 \\
\hline &, 641 \\
\hline
\end{tabular}

$\mathrm{Bu}$ tablo incelendiğinde $\mathrm{A} 1 \quad(0.371<0.40)$ ve $\mathrm{O} 1 \quad(0.379<0.40)$ maddelerinin 0.40 eşik yük değerinin altında kaldığı görülmüştür. Dolayısıyla, bu maddeler çıkarılarak analiz tekrarlanmıştır. Elde edilen ortak varyans değeri Tablo 11'de özetlenmiştir. Tablo incelendiğinde tüm maddelerin eşik yük değerinin (0.40) üzerinde olduğu görülmüss ve analiz işlemi sonlandırılmıştır. Ayrıca tek boyutlu olarak kabul edilen ölçeğin açıkladığı toplam varyans oranı \% 58,501 olarak tespit edilmiştir.

Tablo 11. Sorular Çıkartıldıktan Sonra Elde Edilen Ortak Varyans Değerleri

\begin{tabular}{|c|c|}
\hline Soru & Ortak varyans değeri \\
\hline $\mathrm{A} 2$ &, 637 \\
\hline $\mathrm{A} 3$ &, 705 \\
\hline $\mathrm{A} 4$ &, 782 \\
\hline $\mathrm{R} 1$ &, 829 \\
\hline $\mathrm{R} 2$ &, 830 \\
\hline $\mathrm{R} 3$ &, 781 \\
\hline $\mathrm{R} 4$ &, 810 \\
\hline $\mathrm{K} 1$ &, 822 \\
\hline $\mathrm{K} 2$ &, 674 \\
\hline $\mathrm{K} 3$ &, 772 \\
\hline O2 &, 718 \\
\hline O3 &, 787 \\
\hline
\end{tabular}




\section{SONUÇ}

Bu çalışmada Spor Takımı Evangelizmi (eFANgelizm) Ölçeğinin (STEÖ) Türkçeye uyarlama çalışması kapsamında maddelerin özgün dilden hedef dile çevrilmesi, dilsel ve kavramsal olarak madde eşdeğerliğinin belirlenmesi ve elde edilen Türkçe formun geçerliğinin ve güvenirliğinin hesaplanması işlemleri yapılmıştır.

STEÖ'nin Türkçeye Uyarlanması çalışması sonucunda tek faktörlü yapıya sahip 12 soruluk Ek-1'de detaylandırılan soru formu elde edilmiştir. STEÖ’nin Türkçe formunun güvenilirlik değeri ,936 ve geçerlilik değeri 0,845 olarak belirlenmiştir. Elde edilen güvenirlik katsayısının alanyazında belirtilen ideal güvenirlik aralığının üstünde olduğu söylenebilir (Erkuş: 2005; Creswell: 2005; Field: 2005). Ölçeğin kısa ve anlaşılır cümlelerden oluştuğu, bu nedenle uygulanmasının ve değerlendirilmesinin araştırmacılara kolaylık sağlayacağ düşünülmektedir.

Spor Takımı Evangelizmi (eFANgelizm) Ölçeğinin Türkçe formu, spor takımı evangelizmini ölçmede geçerli ve güvenilir bir araçtır.

\section{KAYNAKÇA}

Aycan, A., Polat, E. ve Uçan, Y. (2009). Takım Özdeşleşme Düzeyi İle Profesyonel Futbol Müsabakalarına Seyirci Olarak Katılım Kararını Etkileyen Değişkenler Arasındaki İlişkinin İncelenmesi. Spormetre Beden Eğitimi ve Spor Bilimleri Dergisi, 7(4), 169-174.

Büyüköztürk, Ş. (2004).Veri Analizi El Kitabı. Ankara: Pegem A Yayıncılık.

Creswell, J. W. (2005). Educational research: Planning, Conducting and Evaluating Quantitative and Qualitative Research. Pearson Prentice Hall.

Dwyer, B., Greenhalgh, G. P., \& LeCrom, C. W. (2015). Exploring Fan Behavior: Developing a Scale to Measure Sport eFANgelism. Journal of Sport Management, 29(6). http://dx.doi.org/10.1123/JSM.2014-0201

Eker Öğüt, G. T. (2010). Futbolun Dayanılmaz Çekiciliği, Büyülenen Taraftar Portresi, Fanatizm ve Beşiktaş. Milli Folklor, 11(85): 173-182.

Erkuş, A. (2005). Bilimsel Araştırma Sarmalı. Ankara: Seçkin Yayınları.

Field, A. (2005). Discovering Statistics Using SPSS. London: SAGE Yayınları

Hanlon, P. (2006). Primal Branding. New York: Free Press.

Matzler, K., Pichler, E. A., \& Hemetsberger, A. (2007). Who İs Spreading The Word? The Positive İnfluence of Extraversion on Consumer Passion and Brand Evangelism. Marketing Theory and Applications, 18, 25-32.

Meriç, N. (1994). Medya Bilgilendirmesi Karşısında Nasıl Tavır Takınmalıyız?, Yeni Dünya Dergisi, Eylül, 1 (12), 30-31.

Orçun, Ç. ve Demirtaş, M. C. (2015). Gelişen futbol ekonomisinde taraftarların kulüp değerlerine olan bakış açıları: Bucaspor örneği. Optimum Ekonomi ve Yönetim Bilimleri Dergisi, 2(1), 113-126.

Pett M. A., Lackey N. R.,\& Sullivan J. J.. (2003). Making Sense Of Factor Analysis: The Use Of Factor Analysis for İnstrument Development in Health Care Research (Illustrated Edition). Sage.

Roberts, K. (2004). Lovemarks: The Future Beyond Brands, NY: Powerhouse Books. 
EK 1: Spor Takımı Evangelizmi (eFANgelizm) Ölçeği Türkçe Soru Formu

\begin{tabular}{|c|c|c|c|c|c|}
\hline & 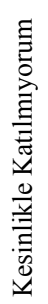 & 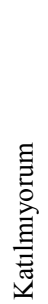 & 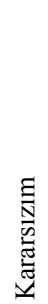 & 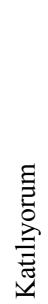 & 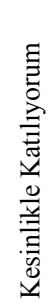 \\
\hline 1. Tuttuğum takımdan "biz" şeklinde bahsederim. & & & & & \\
\hline 2. Çevremdekiler tuttuğum takımın iyi oyuncularından bahsederim. & & & & & \\
\hline $\begin{array}{l}\text { 3. Tuttuğum takım ile ilgili tanımadığım kişilerin konuşmalarına dahil } \\
\text { olurum. }\end{array}$ & & & & & \\
\hline 4. Aracımda tuttuğum takımı belirten ürünler bulunur. & & & & & \\
\hline 5. Ofisimde tuttuğum takımı belirten ürünler bulunur. & & & & & \\
\hline $\begin{array}{l}\text { 6. Doğum günlerinde, özel günlerde tuttuğum takıma ait ürünleri hediye } \\
\text { olarak veririm. }\end{array}$ & & & & & \\
\hline 7. İnternet profillerimde tuttuğum takımı belirtirim. & & & & & \\
\hline $\begin{array}{l}\text { 8. Tuttuğum takımı tutmayan arkadaşlar ve aile üyeleri ile onların tuttuğu } \\
\text { takım kaybettiğinde iletişim kurarım. }\end{array}$ & & & & & \\
\hline $\begin{array}{l}\text { 9. Tuttuğum takımı tutmayan arkadaşlar ve aile üyeleri ile onların tuttuğu } \\
\text { takım kazandığında iletişim kurarım. }\end{array}$ & & & & & \\
\hline $\begin{array}{l}\text { 10. Tuttuğum takımı tutmayan arkadaşlar ve aile üyeleri ile onların tuttuğu } \\
\text { takım oynarken iletişim kurarım. }\end{array}$ & & & & & \\
\hline 11. Tuttuğum takımın maçının olduğu günlerde takım üniforması giyerim. & & & & & \\
\hline $\begin{array}{l}\text { 12. Aynı takımı tutan arkadaşlar ve aile üyeleri ile tuttuğumuz takım } \\
\text { oynarken iletişim kurarım. }\end{array}$ & & & & & \\
\hline
\end{tabular}

\section{SUMMARY}

Developing loyal sport consumers is a fundamental goal of spectator sport organizations. As a result, a great deal of sport management academic research has focused on the concept of sport team loyalty. Brand evangelism, an advanced form of marketing where consumers voluntarily advocate on behalf of the brand, can bring numerous benefits to a firm. Brand evangelism can be defined as the behavior of "spreading positive opinions and trying fervently to convince or persuade others to get engaged with the same brand". Pro-brand behaviors such as word-of-mouth promotion, recruitment of consumers, and disparagement of rivals are just a few of the many actions associated with brand evangelism. Numerous benefits are received by brands with evangelistic consumers, as these individuals promote the brand.

Given the importance of brand evangelism as highly sought after behavior among consumers and in an effort to develop additional means for measuring sport fan behavior, in the purpose of this study, it was aimed to adopt the Sport eFANgelism Scale developed in English in 2015 by Dwyer, Greenhalgh and LeCrom to Turkish. The purpose of the study was to develop and validate a sport 
eFANgelism scale and in doing so create a multidimensional scale to measure loyal fan behavior in Turkey. In the study, eFANgelism was conceptualized as a potentially beneficial form of behavioral loyalty wherein sport fans passionately and/or passively initiate repeated team related practices or communication with others.

Analyses were conducted by using SPSS (Statistical Package for the Social Sciences) version 22. Research data was collected from 550 online users (where $47,3 \%$ male and $52,7 \%$ female; $32,7 \%$ born before $1980,67,3 \%$ born between 1980-1999; 41,8\% bachelor and 58,2\% married; $63,6 \%$ have no child, $27,3 \%$ have one child, 5,5\% have two children and 3,6\% have more than three children; $3,6 \%$ is elementary, $16,4 \%$ is high school, $14,5 \%$ is associate, $27,3 \%$ is undergraduate and $38,2 \%$ is graduate). The survey has been closed when the total number of results have reached 550 .

The Cronbach alpha coefficient of the whole scale was found as ,936 and reliability coefficient estimated from the data of 550 individuals was found as 0,845. In the Turkish version of Sport eFANgelism Scale, two questions were deleted. The original scale has four factors. In the original version, the factors and their definitions were as follows; Advocate This factor embodies the internalization and advocacy of team superiority to others, including strangers. Advertise: This dimension represents the publicizing of team affiliation on automobiles, at work, online, or through gifts to others. Antagonize: This factor encompasses provocative behavior with family and/or friends who are not fans of one's favorite team. Assimilate: This dimension symbolizes outgoing group assimilation, including game day behavior related to special get-togethers, communication, and apparel choice. In the Turkish version the total number of factors has been decreased to one. It is ascertained that there is a one dimensional structure accounting for $\% 58,501$ of total variance.

Findings have shown that Turkish adaptation of the Sport eFANgelism Scale is a reliable and valid instrument that can be used in to measure loyal fan behavior in Turkey. 